\title{
Basic Principles for Managing Intellectual Property in the Digital Environment
}

\begin{abstract}
Editor's Note:
The following document was prepared by the Committee on Libraries and Intellectual Property of the National Humanities Alliance (NHA) in an effort to build consensus within the educational community on the uses of copyrighted works in the digital environment. The American Political Science Association, represented by Executive Director Catherine Rudder, was one of 15 scholarly organizations that participated in the NHA-led discussions resulting in this document. While designed by representatives of primarily institutions within higher education, the principles presented here apply to a broadly defined educational community encompassing many other institutions and individuals, including primary and secondary schools, independent research laboratories, faculty and students, and independent scholars.
\end{abstract}

For more information on the NHA and its efforts, please contact John Hammer, National Humanities Alliance, 21 Dupont Circle, Suite 604, Washington, DC 20036.

\section{Context}

\section{Introduction}

The educational community encompasses a broad range of public and private institutions whose primary missions include research, education, and the preservation of our scientific and cultural heritage. In the process of carrying out their missions, these institutions, which include research universities, colleges, university presses, libraries, scholarly societies, museums, and archives, among many others, are both creators and consumers of scholarly communication. As such, these institutions participate in the full spectrum of activities regulated by the laws governing copyright and must be sensitive to the balance of interests embodied in them. While a degree of consensus has been reached concerning the rights of creators, copyright holders, and users of information in the print environment, new proposals for the copyrights of digital works are threatening to disrupt the balance between the rights of owners and public access in the electronic world.

As they revolutionize the means by which information is recorded, disseminated, accessed, and stored, digital technologies are eliminating the technical limits that have supplemented the legal framework of the balance between ownership and public dissemination: Unlimited technological capacity to disseminate by transmission in ways that can violate the rights of copyright holders confronts equally unlimited technological capacity to prevent works from being used in ways contemplated by law. Carried to its logical extreme, either trend would destroy the balance, with results that would likely undermine core educational functions as well as radically transform the information marketplace.

\section{Scholarly Communication}

The educational community is heavily invested in scholarly communication. This process includes such functions as: exchange of cuttingedge discoveries and works-inprogress among scholars, scientists, curators; publication of new and synthetic works for the broad scholarly community; dissemination of new and existing knowledge to students through teaching; establishment of repositories to enable handing knowledge down from generation to generation; and transmission of knowledge beyond the educational community to the public. It requires the ability to cite and quote the work of others, regardless of format. Whereas quotations from text can be manually transcribed, quotations from digital object may require machine mediation. Scholarly communication involves individuals, academic departments and research units, libraries, archives, university presses, museums, commercial publishers, external research sponsors, academic and industrial software developers, and others.

Because it carries information that ranges from complex graphical and sound data to plain text, and must reach an audience that ranges from Nobel scientists to freshen in remedial courses to citizens visiting a local museum, scholarly communication must include the full range of content and take place in all media. It must flow back and forth between all of its participants and be capable of moving rapidly enough to contribute to the evolution of understanding and knowledge. It must be disseminated through an economically viable system, and it must not be overwhelmed by a permissions system so burdensome that it makes rapid movement impossible.

Scholarly communication is based on an ethic of authorship that both compels publication and condemns plagiarism. It demands accurate attribution and respect for the integrity of works while asserting the importance of evaluating and interrogating sources for cumulative advance of knowledge. By promoting trust between authors, owners, and users, adherence to this ethic facilitates the rapid and broad dissemination of information. Educational institutions have developed organizational structures that insulate faculty, curators, and studentsthe core, but not the only, participants in scholarly communicationfrom direct dependence on economic returns from specific intellectual properties. Instead, they rely first on institutional rewards for their cumulative success in creation and dissemination. The institutions, however, function as both owners and consumers of the intellectual properties that circulate in the process of scholarly communication. As such, some of these institutions, such as museums, university presses, and scholarly societies, depend on the revenue from copyright ownership to support their educational, dissemination, and preservation missions.

\section{The Documentary Record}

New knowledge cannot be created without extensive reference to work already done by others and to the 
accumulated records of human and natural phenomena. Nor can the accumulated collective knowledge of a society be transmitted intact to succeeding generations without its preservation and organization. Libraries, museums, and archives play crucial roles as custodians of knowledge and must continue to do so in order to carry out core educational missions. Faced with an exponential increase in the rate at which documentation is growing, libraries, museums, and archives increasingly seek to exploit the unprecedented storage capacities and facilities for more effective access strategies of digital media. Moreover, the increased data creation and storage capacities generate new pressures on systems for preservation, organization, and access.

Although the functionalities of digital technologies will continue to give rise to practices and relationships that bear little resemblance to those surrounding print, neither novel arrangements nor enhanced capabilities should obscure the fundamental continuity of purpose underlying preservation and organization. The requirements of the academic mission and the accumulation of a cultural heritage do not cease when information and documentation cease to have commercial value and pass out of the marketplace. Hence, relations among copyright holders, educational institutions, and the law must reflect the needs of the future as well as the present and should acknowledge the added value to society of preservation and of well-ordered systems for navigating information.

\section{Approaches to Change}

During 1995 and 1996, the U.S. Congress and the World Intellectual Property Organization (WIPO) worked to revise intellectual property law to address issues raised by the still evolving digital environment. Domestic legislation died in subcommittee during the second session of the 104th Congress amidst contentious debate. Internationally, the WIPO treaties proved more supportive of the principle of balance between the rights of owners and the need for public use. But the treaties must now return to the U.S. for rati- fication and the possible development of implementing and related legislation.

The educational community urges that changes in the law be carefully crafted to enhance rather than impede the rich and timely circulation of information as well as its preservation and organization. The educational community recognizes the difficulty of prescribing a priori practices for a digital environment in which:

commercial, academic, and public practice is still experimental and fluid;

works as different as software, research reports, textbooks, primary text sources, visual art, and sound recordings are included;

a volatile set of technologies for protection, dissemination, and tracking is being developed, whose implications are often not clear; and

a wide variety of formats and media is involved.

Working on the frontiers of technological, economic, and legal knowledge, the educational community seeks opportunities for experimentation with new institutional arrangements for managing the dissemination and preservation of knowledge contained in copyrighted and public-domain works. It also seeks a legislative and economic environment that fosters collaboration and a search for consensus rather than confrontation and litigation.

In preparation for the ongoing legislative debates on intellectual property in the digital environment, the educational community believes it necessary to develop its own consensus on a common set of broad principles which would provide standards against which coalitions and individual institutions can evaluate legislative proposals. Faced with the strong interests of the info-tainment industry to maintain tight control of intellectual property in a global marketplace, the educational community may strengthen its more balanced position by speaking with one voice informed by the principles. The following principles are based on the "University of California Copyright Legislation and Scholarly Communi- cation Basic Principles, Working Draft, December 2, 1996."

\section{Principles}

The educational community approaches pending changes in copyright and neighboring intellectual law (e.g., Sui Generis Database Protection Act) with the overriding conviction that it is in the interest of the evolving U.S. information society that the legal environment foster rather than disrupt the balance between intellectual property owners and the public good that is embodied in current law.

\section{Copyright law provisions for digi-} tal works should maintain a balance between the interests of creators and copyright owners and the public that is equivalent to that embodied in current statute. The existing legal balance is consonant with the educational ethic of responsible use of intellectual properties, promotes the free exchange of ideas, and protects the economic interests of copyright holders.

Intellectual property is a significant form of social capital, whose growth depends on its circulation, exploitation, and use. As a major arena in which intellectual property is created and disseminated, educational institutions have nurtured an ethic of intellectual property based on:

- respect for the rights of creators and copyright owners;

- accurate attribution and respect for integrity;

- guarantees of preservation;

- promotion of dissemination and access; and

- economic viability of the scholarly communication system.

This ethic complements the provisions of copyright law, which provide one form of protection for certain kinds of intellectual properties and a framework for their dissemination that encompasses all sectors of society, including both market and nonmarket transactions.

Existing copyright law recognizes the tension between the needs of society and the rights of creators by permitting a defense against charges 
of infringement for certain uses of copyrighted works as specified in sections 107-1 10 of the U.S. Copyright Act of 1976. Among these uses are: the fair use of copyrighted works for teaching, scholarship, or research, among other activities; the reproduction of copyrighted works by libraries and archives under certain conditions for specific purposes; and the performance or display of a work by instructors or pupils in the course of face-to-face instruction. Equivalent qualification of owners rights should be extended into the digital environment with appropriate safeguards against abuse.

- These principles should be independent of particular technologies. Current statutory language embodies some of them in detailed prescriptions for specific practices in the print, tape, and broadcast environment. These are based on the print context in which the same object-a copy-is used to store, distribute, and use a work, and the simultaneous performance of more than one function (e.g., storage and distribution) requires the creation of more than one copy. In the digital environment, storage, distribution, and use are accomplished by algorithms instead of copies, and practices sanctioned by law in the paper environment may have significant unintended consequences. Accordingly, legislative efforts to extend print practices into the digital environment should focus on objectives rather than on strictly analogous practices.

\section{Copyright law should foster the} maintenance of a viable economic framework of relations between owners and users of copyrighted works.

The rich and timely circulation of information-regardless of whether it is contained in physical or electronic media-underlies the educational mission. It depends upon a viable publishing industry to promote communication across institutional and disciplinary boundaries and upon a sustainable library system to store, preserve, organize, and provide access to information. Other institutions, such as museums and historical societies, depend on a reli- able source of revenue from their copyrighted collections to support their equally important stewardship responsibilities.

- To this end, the educational community supports the use of copyright ownership to enable publishers, creators, and owners to secure reasonable returns on investments in intellectual products and sustain their enterprise.

- Management of rights should encourage a reasonable balance between the cost of permission seeking and the use for which permission is sought.

- The educational community opposes extensions of copyright protection that would suppress fair competition or allow monopolies to prevent users from accessing and using information in an economical and convenient form. (For example, the proposed Sui Generis Database Protection Act, with its perpetually renewing rights, could suppress fair competition. In addition, excessive extension of copyright term could have the same effect.)

- Debate over whether and how the first sale doctrine should be applied to digital works is ongoing. Its resolution is likely to involve a complex combination of technical, legal, and business measures. Under existing law, the doctrine of first sale permits the legal purchaser of a copy of a work to dispose of it in any way the purchaser wishes, including reselling, lending, or giving it to others. The ability of libraries to lend is based on this doctrine. Because digital works can be instantly reproduced and transmitted-e.g., posting on a Web site for browsing-while an "original copy" is retained, many copyright owners fear that extension of first sale rights into the digital environment will destroy their markets. Some have sought to protect their products by asserting that they are licensed rather than sold and that these works can be used only as the licensee prescribes. Concerned that license restrictions will prohibit the digital equivalent of examining the contents of or borrowing a book or journal without purchase, some libraries argue that a digital first sale equivalent is essential to the teaching and research enterprise. Emerging technologies not yet in the commercial marketplace may provide a means of simulating first sale conditions with "envelope" or "lockbox" software, but it is not yet possible to predict whether they can be applied in desirable ways that are acceptable to consumers.

\section{Copyright laws should encourage enhanced ease of compliance rather than increasingly punitive enforce- ment measures.}

The law should create an environment that provides incentives for simplified rights clearance and payment while preserving the principle of fair use contained in current law. Burdensome and inconclusive permissions system may stifle dissemination of copyrighted works or encourage widespread violation of the law, as may undue constriction of fair use exemptions. In extending copyright law and practice to the digital environment care should be taken that the creation of new rights does not become a disincentive to the circulation of information.

- Copyright law should provide a framework for voluntary contractual agreements that both provide fair returns to copyright owners and create incentives for broad dissemination of information. The law should not permit such contracts to abrogate fundamental legal guarantees, however.

- The law should permit the fair use defense in a contractual environment. At the same time, the law should encourage the application of fair use principles to digital works in a manner that maintains respect for the rights of copyright owners consistent with the provisions of current statute.

- The development and use of automated rights tracking, security technologies, and licensing mechanisms may reduce incentives for many kinds of infringement while simultaneously facilitating enhanced access to copyrighted works of others. Copyright law should encourage such innovations. 
- Careful consideration should be given to the advantages and disadvantages of compulsory licensing schemes which require copyright owners to permit certain kinds of uses of their properties and automatically collect fees to pay for such use. Compulsory licensing provisions are already in effect for the broadcast of audio recordings of music. Broader application of this concept has not been thoroughly discussed, and it is premature to advocate for or against such a system for digital works.

4. Copyright law should promote the maintenance of a robust public domain for intellectual properties as a necessary condition for maintaining our intellectual and cultural heritage.

The public domain is an intellectual commons that is the essential foundation for an informed and participatory society. It is critical for education, research, and the creation of new knowledge. With copyright terms extending for periods that can exceed 100 years (life of the author plus 50 years), the digital format in which a work is first fixed is likely to become obsolete long before the copyright expires. Security technologies used to protect copyrighted works from unauthorized use will exacerbate this danger if provision is not made for "unlocking" the work at the appropriate time.

- Information created by governments and public agencies, including under contract, should reside in the public domain as they do under current law.

- Privately created works that have passed a certain age should reside in the public domain as they do under current law.

- Copyright terms should expire on dates that are certain and easy to determine.

- Copyright law should assure that new technologies do not impede the passage of works into the public domain as contemplated by current law.

- Copyright law should facilitate preservation and migration to new media as technologies change. The educational community encourages a distinction between activities necessary for preservation and storage and activities to provide access to copyrighted works. Because technology evolves rapidly, the statutes and regulations governing preservation and storage should be flexible enough to apply to successive generations of technology.

5. Facts should be treated as belonging to the public domain as they are under current law.

The educational mission requires that all who are engaged in it be able to examine and analyze facts without restriction. Compilations of facts that are creative or add value may be protected by copyright, but the facts themselves are and should remain in the public domain.

6. Copyright law should assure that respect for personal privacy is incorporated into access and rights management systems.

Academic freedom and the Constitutional guarantees of freedom of thought, association, and speech require that individual privacy be respected. In the print environment, individuals may examine works in libraries and examine and purchase them in sales outlets without leaving records of their identities. The educational community urges that legislation be crafted to assure that the rights of individuals to access copyrighted works without recording personal identities and comparably protected in the digital environment.

7. Copyright law should uphold the principle that liability for infringing activity rests with the infringing party rather than with third parties. Institutions should accept responsibility for acts undertaken at their behest by individuals but should not be held liable for the acts of individuals-whether or not associated with the institution-acting independently. This principle is an essential underpinning for academic freedom.

The creation and dissemination of knowledge depends on a community of individuals who develop their own scholarly investigations and syntheses. Such a community can only be sustained if the tenets of academic freedom, including freedom of speech and rejection of prior restraint, are upheld. The educational community opposes copyright legislation that would make institutions liable for the acts of individuals acting on their own initiative, or that would impose prior censorship. Copyright enforcement provisions should uphold principles of due process in determining whether specific allegations of infringement are valid. Educational institutions accept responsibility for establishing policies, carrying out due process when appropriate, and creating climates in which all those who use their facilities and resources use copyrighted materials appropriately.

8. Educational institutions should foster a climate of institutional respect for intellectual property rights by providing appropriate information to all members of the community and assuring that appropriate resources are available for clearing rights attached to materials to be used by the institution, e.g., in support of distance learning.

As creators and repositories of vast amounts of intellectual property, educational institutions have both a responsibility and a need to assure that their own institutional practices conform to the requirements of intellectual property law and that their constituencies are well informed about their responsibilities. Institutional practices should set high standards for compliance and can serve as an educational tool for heightening the consciousness of individuals within the educational community of what the law demands. Assurance that institutional practices are fully aligned with legal requirements will strengthen the position of educational entities in negotiating legislative and contractual conditions.

9. New rights and protections should be created cautiously and only so far as experience proves necessary to meet the Constitutional provision for a limited monopoly to promote the "Progress of Science and useful Arts."

Sui generis protections should be considered with extreme care and only after an adequate body of case 
law has accumulated to define the dimensions of what is at stake. Extension of copyright to new classes of works should be regarded with skepticism until it is demonstrated that the extension affirms the traditional balance between owners and users, and care should be taken to consider whether other bodies of law might be more appropriate vehicles for the protection sought and what the consequences of such applications might be.
10. Copyright enforcement provisions should not hinder research simply because the products of a line of inquiry might be used in support of infringing activity.

While the law should provide penalties for acts of infringement, attempts to criminalize the possession or acquisition of technologies or devices that might be used for illegal purposes will sweep with too broad a broom. Both applied and basic research related to encryption technol- ogies and computer science may require that researchers be able to obtain state-of-the-art devices in order to participate in the creation of new knowledge. Moreover, decryption technologies may be necessary to place works in the public domain at the expiration of copyrights or to engage in legitimate activities, e.g., preservation. Legal sanctions should be reserved for those activities that violate or directly support violation of the law. 